\title{
Outdoor Thermal Comfort Study on a District Level as Part of the Housing Programs in Abu Dhabi and Al Ain, United Arab Emirates
}

\author{
Lindita Bande*, Rahma Adan, Kim Young, Raghad Ghazal, Mukesh Jha, Amna Aldarmaki, Atmah Aldhaheri, \\ Asma Alneyadi, Sharina Aldhaheri and Mira Khalifa
}

Citation: Bande, L.; Adan, R.; Young, K.; Ghazal, R.; Jha, M.; Aldarmaki, A.; Aldhaheri, A.; Alneyadi, A.; Aldhaheri, S.; Khalifa, M. Outdoor Thermal Comfort Study on a District Level as Part of the Housing Programs in Abu Dhabi and Al Ain, United Arab Emirates. Land 2021, 10, 264. https://doi.org/10.3390/ land 10030264

Academic Editor:

Cristina Branquinho

Received: 1 February 2021

Accepted: 2 March 2021

Published: 5 March 2021

Publisher's Note: MDPI stays neutral with regard to jurisdictional claims in published maps and institutional affiliations.

Copyright: (c) 2021 by the authors. Licensee MDPI, Basel, Switzerland. This article is an open access article distributed under the terms and conditions of the Creative Commons Attribution (CC BY) license (https:/ / creativecommons.org/licenses/by/ $4.0 /)$.
Architectural Engineering Department, United Arab Emirates University, Al Ain 15258, United Arab Emirates; r-hassan@uaeu.ac.ae (R.A.); youngki.kim@uaeu.ac.ae (K.Y.); 201870086@uaeu.ac.ae (R.G.); mukeshjha@uaeu.ac.ae (M.J.); 201515555@uaeu.ac.ae (A.A.); 201707568@uaeu.ac.ae (A.A.); 201708441@uaeu.ac.ae (A.A.); 201600367@uaeu.ac.ae (S.A.); 201706823@uaeu.ac.ae (M.K.)

* Correspondence: lindita.bande@uaeu.ac.ae; Tel.: +971-(0)-54779-2797

\begin{abstract}
The United Arab Emirates (UAE) has witnessed fast growth in urban development in the past four decades. A plan to build 7270 houses by 2021 has been initiated by the local authorities. Different local sustainability guidelines are being implemented, including the Public Realm Manual in Abu Dhabi. These local guidelines are tailored to consider the hot and arid climate of the UAE as well as the applied materials, the inclusion of greenery, shading devices, etc. Dubai, Abu Dhabi, and $\mathrm{Al}$ Ain are cities that have imposed the application of such guidelines. Additionally, the newly developed housing programs match the governmental plan. To understand the effect of these design programs on the outdoor thermal comfort (OTC), further investigations are necessary for each city. The most widely built prototype is detached villas, which result in untreated waste areas without shading or greenery. In the old local neighborhoods, Arabic houses were built next to each other to maximize the shading and to ease pedestrians' walkability. This study aims to examine the districts where the housing programs are applied and to determine the most effective strategy to minimize the outdoor air temperatures and enhance walkability. The methodology implements the following processes in order: district analyses of the buildings as well as the externally applied materials, microclimate site measurements, ENVI-met (main software used) models of the current and future scenarios, results and recommendations. The strategies have different impacts in both cites due to the microclimate and other conditions.
\end{abstract}

Keywords: outdoor thermal comfort; hot arid climate; ENVI-met; site measurements; housing program

\section{Introduction}

Since the formation of the United Arab Emirates (UAE) in 1971, a huge jump in economic and urbanization growth has been witnessed. Many environmental issues have been recorded due to the rapid development, unsustainable lifestyle, low energy prices, and extreme climatic conditions, which have led to the UAE having one of the highest carbon footprints and the highest energy consumption per capita in the world [1,2]. Buildings consume around $70 \%$ of the UAE's total energy, which is mainly used for cooling systems, compared to the global average of $40 \%$ [3]. The residential building sector forms the dominant part of the construction industry and has a significant energy consumption and share of carbon emissions [4,5]. It consumes about $30 \%$ of the total electricity in the UAE, making it the second-highest energy consumer [6].

The UAE has one of the world's most generous government programs that aims to provide decent housing for each Emirati citizen [7]. The main residential forms being developed are extensive housing programs that are provided by the government to its 
citizens and rental housing projects. For UAE citizens, the government is the main housing provider at the local and federal levels. According to the citizens' culture and preference, most of the housing programs are in the form of detached houses (also known as villas), which has resulted in the villa stock increasing by 300\% from the year 2000 to 2009 [8]. In the extreme hot and arid climate of the UAE and other Gulf countries, this housing prototype demands the most in terms of cooling [9]. Recent research showed that around $79 \%$ of the total annual electricity of a typical villa in Abu Dhabi, UAE, is consumed by the cooling system and is estimated to be $219 \mathrm{kWh} / \mathrm{m}^{2}$ [1]. Another study showed that around $37 \%$ of the total annual electricity of a two-story residential building in Al Ain city, UAE, is consumed by the cooling system and is estimated to be $186 \mathrm{kWh} / \mathrm{m}^{2}$. Abu Dhabi is a coastal city with higher levels of humidity compared to AL Ain city. Al Ain is located in the border with Oman and the air is relatively dry during summer and winter [10].

$\mathrm{Al}$ Ain's climate is dominated by high temperatures and plentiful sunlight during the year. Throughout most of the year, the high temperatures exceed the comfort zone range, and the National Bureau of Statistics recorded the maximum average annual temperature to be $45^{\circ} \mathrm{C}$ in August with a minimum of just $13^{\circ} \mathrm{C}$ in January [11]. The outdoor microclimate has an impact on humans' comfort and health as well as the usage of outdoor areas. Additionally, the high air temperatures can reduce mental and physical performance, which is a major problem, especially in hot arid and hot humid climates [12].

The design of outdoor spaces can significantly improve the outdoor thermal comfort (OTC), especially the detailed design of shading devices, surface materials, greenery, and water surfaces (combined, referring to this study). Different studies have been conducted to analyze the impact of design parameters on the OTC. Two summer scenarios were studied in Great Athens to examine twelve different outdoor spaces using two thermal comfort approaches. The results indicated that the use of greenery, water surfaces, and highly reflective and emissive surface materials improved the OTC [13]. Another study in Dubai examined the importance of projects' orientation in open land. The air temperature and the impact of wind on the OTC of different alternatives were simulated using ENVI-met software. The results revealed that the staggered formation of buildings encouraged faster wind speeds when compared with a solid edge [14].

Another study conducted by Ahmed investigated the impact of the urban configuration, proportion of the courtyard, buildings' height, and orientation on the OTC in a military camp in Abu Dhabi, UAE. The simulation results of ENVI-met 4.0 software indicated that the effect of the height and orientation were negligible when compared to the urban configuration and courtyard proportion, which significantly decreased the air temperature and improved the OTC [15]. Hamdan and de Oliveira examined the effect of urban design strategies, including the canyon ratio (ratio of the building height to street width), orientation, vegetation shading, and wind speed, on the microclimate of Al Ain City, UAE. The Universal Thermal Climate Index (UTCI) was simulated using Grasshopper along with OpenStudio, EnergyPlus engine, and Radiance plug-ins. It was recommended to have a 1:2 canyon ratio, north-south path orientation, shading devices, and to create a wind passage to reduce the UTCI and increase comfort [16].

Baca and Tsai focused on analyzing the impact of the building shading on the OTC in Abu Dhabi, considering both the buildings' height and density. It was concluded that the optimum solution to improve the OTC is to increase the building height-to-width ratio [17]. Another study evaluated the outdoor evaporative surfaces in an outdoor campus courtyard in Abu Dhabi. The results proved that the evaporative surfaces are capable of improving the OTC and reducing the UTCI significantly [18].

Nikolopoulou and Steemers suggested that the physical world and psychological adaptation are parallel instead of contradictory. Issues were based on naturalness, perceptions, experience, exposure time, monitoring and environmental simulation. It was established that various methods depend on different seasons. However, both psychological and physical adaptation can be broadened by delivering a variety of spaces for diverse settings. Physical environment and psychological adaptation have to be seen as 
complementary when analyzing OTC. They cannot be seen as contradictory parameters. Therefore, it would be beneficial to improve outdoor spaces and increase interaction between people. Even though the physical parameters impacting the OTC can be measured, it has proven that measuring the psychological adaptation to the outdoor space treatment is difficult to measure. Largely personal parameters impact the psychological adaptation to the outdoor thermal comfort. The use of the outdoor spaces throughout the year can have a positive impact on people's psychology. This gives importance to the treatment of microclimate in designing of urban spaces $[19,20]$.

The balance between the use of vegetation and shading devices in a landscape development in and urban area is a complex process. In a study conducted in downtown Abu Dhabi, on five different district typologies, it was found that shaded devices integrated with vegetation have a higher impact on improving OTC rather than vegetation. Reviving the parking areas between building blocks in the city of Abu Dhabi is an ongoing research project; however, some district has been improved by adding vegetation and urban shading devices. Historically, buildings in the Middle East were built close to each other in order to create shade in the streets and make them more walkable during the hottest hours of the day. Excessive solar radiation increases the air temperature and therefore the outdoor thermal comfort. The low-rise buildings in the modern neighborhoods are built far from each other, enabling the streets to have shading form these structures. Therefore, the re-design of urban spaces in these cities is relevant to improving OTC. Masdar City is an exceptional case of adapting the Arabic historical lesion in improving the OTC. The use of vegetation in the hot arid climate requires irrigation that is provided from the desalination process, a costly, time-consuming process. Shading structures combined with vegetation, trees grown in the local environment, is proven to be a sustainable approach to the urban spaces treatment and improving the microclimate [21,22].

Referring to a study conducted in Jeddah, Saudi Arabia (hot arid climate), it was found that the majority of the interviewed occupants emphasize the relevance of the use of the shaded areas. The shaded areas reduce the high risk of extreme heat stress. The occupants defined that shading is a must in outdoor spaces; alternately, the same outdoor space without shading would not be used. The preferred shading structures are tensile (improve the wind flow) and integrated into the urban context. The urban contest has an impact on the levels of outdoor thermal comfort. The street pattern, the building height and geometry model the microclimate and therefore the OTC [23,24].

Predicted Mean Vote (PMV) is one of the parameters used to measure levels of outdoor thermal comfort. PMV considers the activity type, level of clothing, air temperature, relative humidity, wind flow and mean radiant temperature. Based on the classification showed in Table 1 , the values vary from -3 to 3 [25].

Table 1. Levels of Predicted Mean Vote (PMV), thermal perception and grade of psychological stress.

\begin{tabular}{ccc}
\hline PMV & Thermal Perception & Grade of Physiological Stress \\
\hline$>3$ & Broiling hot & Extreme heat stress \\
\hline 3 & Hot & Strong heat stress \\
\hline 2 & Warm & Moderate heat stress \\
\hline 1 & Slightly warm & Slight heat stress \\
\hline 0 & Comfortable & No thermal stress \\
\hline-1 & Slightly cool & Slight cold stress \\
\hline-2 & Cool & Moderate cold stress \\
\hline-3 & Cold & Strong cold stress \\
\hline$\leq 3$ & Very cold & Extreme cold stress
\end{tabular}


Local guidelines such as the Public Realm Manual in Abu Dhabi give instructions on how to treat outdoor spaces in urban areas. The typology of trees used in urban areas is based on the local climate (irrigation, resistance to the harsh weather, typology of shading devices to be used in urban spaces, in mail streets). However, the guidelines are generic and each district typology has a different microclimate. The city of Abu Dhabi has higher humidity levels compared to the city of Al Ain. Therefore, this study aims to investigate the impact of the vegetation and shading structures in these two microclimates [26].

\section{Methodology}

The aim of this study is to investigate the best scenario/strategy to improve the OTC in two selected neighborhoods, Al Ain and the Abu Dhabi District. The investigation adds information to the current standards and guidelines in terms of retrofitting cities (by analyzing OTC before applying a certain strategy). Within the same country, the cities have different microclimates. Therefore, the strategies used in urban areas have different impacts on the OTC. The methodology follows the below path (Figure 1). The first step is the selection of the districts to be analyzed. Due to the available data, the two districts are part of a Governmental Housing Program. Both districts have the same strategies applied in order to understand if they have different outcomes. The strategies are based on a combination of trees and shading structures applied in the walking paths or courtyards of the neighborhoods. The trees studied (applied in the simulation models) are local trees, and the shading devices refer to a structure analyzed in a previous study done for the OTC study of downtown Abu Dhabi [21].



Figure 1. The methodology followed in this study for both the Al Ain District and Abu Dhabi District.

The second step is taking site measurements for the boundary conditions of the CFD (Computational Fluid Dynamic) software used in this study. The site measurements are also used to validate the models. In both cases, the sensor measurements used are air temperature, relative humidity and wind speed. In the Al Ain case study, the sensors were part of the United Arab Emirates University (UAEU) campus, and in the Abu Dhabi case study, the sensors are located in the southwest area of the main island.

The modeling and simulations are done by using two different tools. The Auto CAD software is the first tool used to prepare the base (2D plans) for the models used in ENVI met. The ENVI met is the second software used in this study. This is a CDF software where the modeling, simulation and post-processing is done. The software modeling environment has been modified in order for the models to be more accurate based on the data collected. The boundary conditions that use the site measurements are an input to the models before the simulation process starts. The software has a post-processing environment that calculates the PMV. 
The last points of the methodology are the results and the analysis of the outcome. The values taken from the post-processing environment of ENVI-met (the first part of the analysis is done in Biomet and then in Leonardo, both part of the ENVI-met environment) are analyzed through matlab (a software that can perform the post-processing of data). The results are taken individually for each district analyzed in terms of PMV. Other relevant factors such as relative humidity are also analyzed in the results. Afterwards, a comparative analysis between the best scenarios of both case studies is done [27,28].

The main points of the methodology are mentioned below:

- District selection/scenario evaluation

- Weather conditions

- $\quad$ Site measurements

- $\quad$ Modeling and simulations

- Results

\subsection{District Selection/Scenarios Evaluation}

The district selection is based on the available data from the housing program by the UAE Government. The improvement of the walkability by improving the outdoor thermal comfort is an important goal of the government as per the Abu Dhabi Plan 2030 [22]. Referring to previous studies, the main elements used in the landscape with the aim of improving the OTC in the region are trees and shading structures. In both case studies, the selected houses do not create shade on the streets. They are built with considerable distance between each other and from the pedestrian walking path (in comparison with old Arabic architecture where buildings were built close to each other and they would shade the walking paths). Therefore, there is a need to protect the residents from the excessive sun mainly during the spring, summer and autumn seasons [29]. There are several elements contributing to the improvement of the OTC in a neighborhood, such as air temperature, mean radian temperature, relative humidity, wind speed, evapotranspiration process, perception or feeling of the pedestrian walking on the specific path and the weight and type of the clothes the pedestrian is wearing. In this study, the PMV index is selected over other indexes as it is a free option in the free version of the software used for the modeling and simulations (ENVI-met 4.0) [23]. Regarding the district selection, the Al Ain District is located near AL Ain City in a town called al Shiwayb. This town is located on the border with Oman. The villas are detached and the street pattern is linear. Meanwhile, the second district is located in Abu Dhabi, a coastal city. The vilas here are also detached but the street patter is more organic. In both cases, the private areas and the public areas are partially treated with the landscape or shading. Most of these areas have natural sand. Figure 2 shows where these neighborhoods are located (the red marking shows the neighborhoods and the orange the city of Al Ain and Abu Dhabi. Figure 3 shows the study area within the neighborhood and Figure 4 the specific study area.


Figure 2. Location of Al Shiwayb, Al Ain and New Al Falah, Abu Dhabi, in relation to the cities. 

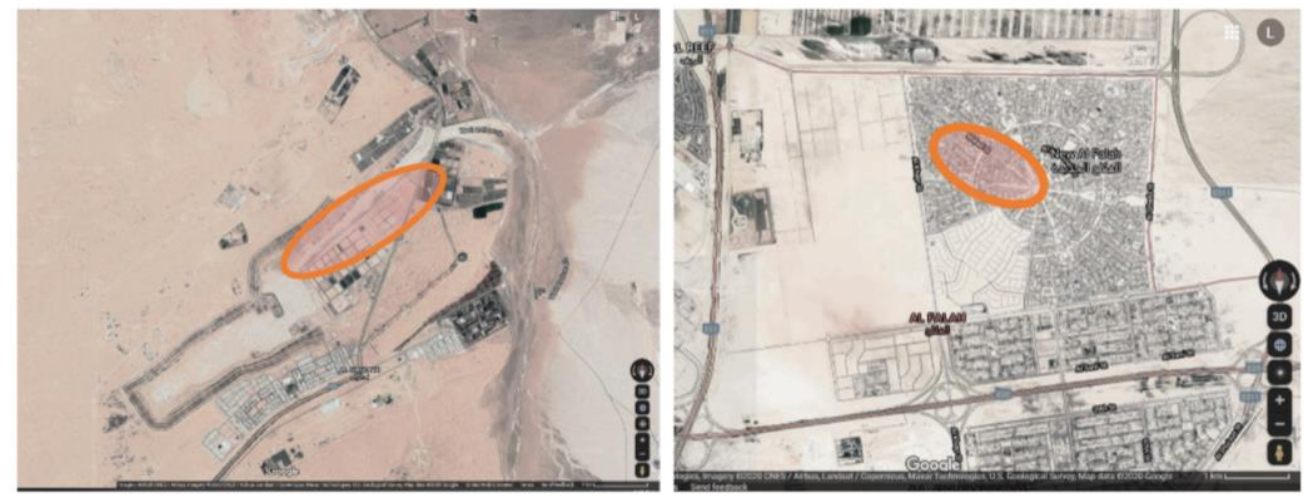

Figure 3. Neighbourhood in Al Shiwayb, Al Ain and Neighbourhood in New Al Falah, Abu Dhabi.


Figure 4. Study area in Al Shiwayb, Al Ain and in New Al Falah, Abu Dhabi.

Improving the OTC is an important goal in the Estidama 2030. This is a guideline developed from Abu Dhabi Urban Planning Council for sustainable building construction/operation and sustainable communities. In this guideline, there is a provision in cooling the city of Abu Dhabi through strategies such as vegetation and shading devices. Both strategies are elements that can improve the OTC. Currently, several neighborhoods in the city have started applying these strategies. This study is an attempt to evaluate an optimal combination of both strategies in obtaining the best values of the OTC, in our case in low-rise districts. The aim is to understand which strategy (trees or shading devices) would work better in obtaining the best PMV values. The two districts are located in slightly different climate conditions. The main factor that changes in these two districts is the relative humidity. Table 2 shows the different scenarios considered in this study [21].

Table 2. Scenario distribution for the Al Ain District.

\begin{tabular}{ccccc}
\hline \multicolumn{5}{c}{ Scenarios Distribution for Al Ain District. } \\
\hline & Green $\left(\mathbf{m}^{\mathbf{2}}\right)$ & Shaded $\left(\mathbf{m}^{\mathbf{2}}\right)$ & Green $(\%)$ & Shaded (\%) \\
\hline Scenario 01 & 94,294 & 0 & 100 & 0 \\
\hline Scenario 02 & 75,873 & 18,421 & 80 & 20 \\
\hline Scenario 03 & 56,577 & 37,717 & 60 & 40 \\
\hline Scenario 04 & 36,089 & 58,205 & 38 & 62 \\
\hline Scenario 05 & 17,111 & 77,183 & 18 & 82 \\
\hline Scenario 06 & 0 & 94294 & 0 & 100 \\
\hline
\end{tabular}


The difference between the scenarios is mainly in the percentage of trees and shading devices used in order to understand the optimal proportion for an optimal PMV value at the specific season/day considered in this study. The trees refer to the local characteristic trees, and the shading devices are a representation of wooden pergolas typically used in the Abu Dhabi parks. Scenario 1 has 100\% vegetation (green) in all the available areas, such as neighborhood parks, the areas along the path walks, and internal gardens in the villas. The vegetation in this study is represented by local trees that are more resistant to harsh summers and require less irrigation. However, they create a considerable amount of shading in the areas where they are located. In this scenario, the percentage of the shading structures is 0 . The shading structures in this study are wooden structures with a height of $3.5 \mathrm{~m}$. In Scenario 2, this proportion between vegetation and shading is 80/20; in Scenario 3, this proposition is 60/40; in Scenario 4, the proportion is 38/62; in Scenario 5 , this proportion is $18 / 82$. In Scenario 6 , the proportion of vegetation and shading is the opposite to that of Scenario 1, meaning that all available areas considered for this study are covered by shading devices. This is a hypothetical scenario to understand the impact of such structures on the microclimate and therefore the OTC.

All of the above scenarios must be adapted in a realistic environment within the modeling software. The software used for the modeling and simulation is CFD. This means that the PMV values that will be the outcomes of the simulation considered in each scenario, for both case studies. For example, other automatically considered parameters beside the relative humidity are the dry bulb temperature, wet bulb temperature and the evapotranspiration process from the trees. In the ENVI-met environment, the wind velocity, the turbulences created by trees, buildings or shading devices are also analyzed. In the modeling of the trees, the shading of the leafs is calculated from the software. The modelled trees (modified from original NEVI-met template) have the characteristics of local trees, which consume less water and are more resilient to the hot arid summers of the region. Meanwhile, the wooden structures have a height of $3.5 \mathrm{~m}$, similar to structures used in Abu Dhabi parks, and they have adapted albedo to real wood (modified from the original ENVI-met template). The modeling of the shading is done with interruption from one unit to the other in order to improve ventilation.

Figure 5 shows scenario1 for each district in graphic software such as AUTO CAD, Figure 6 shows scenario 2, Figure 7 shows scenario 3, Figure 8 shows scenario 4, Figure 9 shows scenario 5, Figure 10 shows scenario 6. The vegetation is represented in green, the shading in red and the houses in black. The scale and the north are also shown in each image. This graphic representation gives a visual overview in the changes from one scenario to the other. The Al Ain District (total district area $302,869 \mathrm{~m}^{2}$ ) is slightly bigger than the Abu Dhabi District (total district area 242,564 $\mathrm{m}^{2}$ ). Although in the plan the housing units appears to be linear, the Al Ain District is part of a bigger system composed of several linear neighborhoods. Meanwhile, the Abu Dhabi District is part of a radial system that includes several neighborhoods. This ratio distribution is an attempt to understand which strategy percentage has better results. Although it is a schematic distribution, the combination of scenarios rationalizes the impact on the OTC. On several occasions, $100 \%$ of one strategy is used over the other in the city of Abu Dhabi [30]. 



Figure 5. ENVI-met 3Dimension of scenario 1, for the Al Ain District and Abu Dhabi District (model scale $100 \times 100)$.


Figure 6. ENVI-met 3Dimension of scenario 2, for the Al Ain District and Abu Dhabi District (model scale $100 \times 100)$.


Figure 7. ENVI-met 3Dimension of scenario 3, for the Al Ain District and Abu Dhabi District (model scale $100 \times 100)$ 



Figure 8. ENVI-met 3Dimension of scenario 4, for the Al Ain District and Abu Dhabi District (model scale $100 \times 100)$.
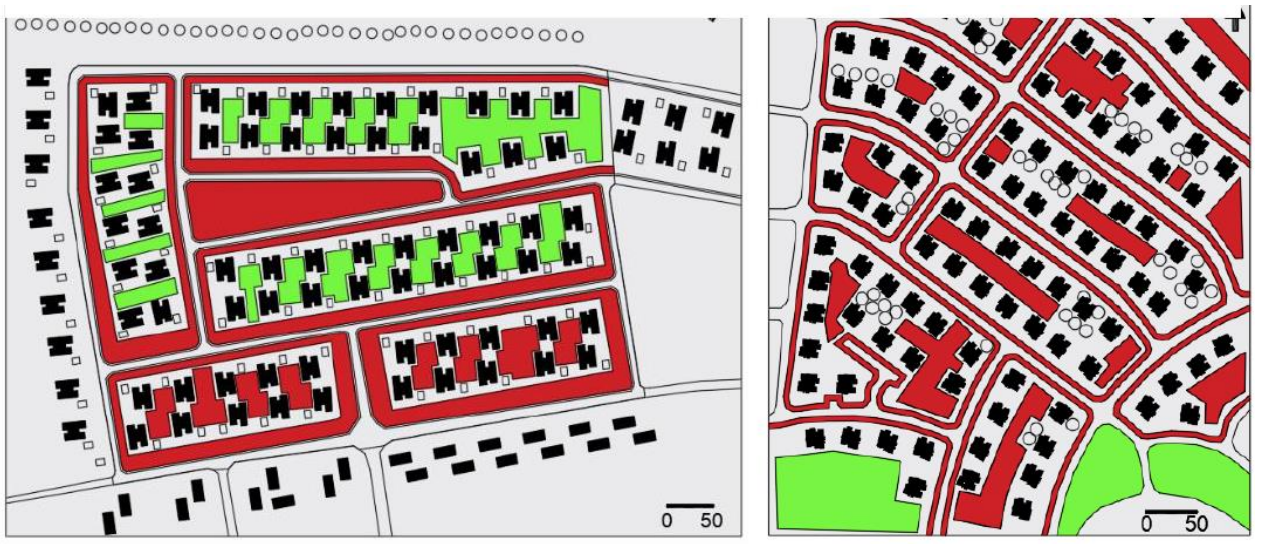

Figure 9. ENVI-met 3Dimension of scenario 5, for the Al Ain District and Abu Dhabi District (model scale $100 \times 100)$.


Figure 10. ENVI-met 3Dimension of scenario 6, for the Al Ain District and Abu Dhabi District (model scale $100 \times 100)$.

\subsection{Weather Conditions}

The UAE has a hot arid climate. Referring to a study based on average data from 1999 to 2019, the average temperature for the city of Abu Dhabi in August is 35.3 degrees Celsius and the lowest average temperature occurring in January is 19.4 degrees Celsius. Meanwhile, for the city of Al Ain, the temperature in July is 36.4 degree Celsius, and in 
January the average temperature is 17.7 degrees Celsius. However, the relative humidity has different values in coastal cities compared to desert cities. Dubai, Abu Dhabi and other coastal cities of the countries have high humidity values. Meanwhile, in cities located in the desert zones, such as Al Ain, the air is dry. The humidity in Abu Dhabi in August is $52 \%$, and in January it is $63 \%$. Meanwhile, the city of Al Ain in July and August has a humidity of $27 \%$, and in January it is $51 \%$. The summer is from June to September, autumn from September to December, winter from December to March and spring from March to June. The spring and autumn have similar characteristics. There are sandstorms and sporadic rain [31].

\subsection{Site Measurements}

The site measurements for the boundary conditions of the ENVI-met models are taken at two different locations for each case study. The boundary conditions with the respective values are shown in the annex. For the Al Ain case study, the sensors considered are located at the United Arab Emirates University (UAEU) campus, Al Ain. The sensors were calibrated prior to recording the data. The distribution on the campus refers to a research project, and each unit is installed in an open area within the walking paths. This is the closest city to the study area. Meanwhile, for the Abu Dhabi case study, the sensors are taken from a global network of measurements available online. The sensors are located in the Bateen area on the main island of the capital. Both site measurements refer to a typical summer day, 18 June 2019. This day was selected due to the available data and due to the relevance of a typical summer day on the OTC. The measurements were hourly averaged values. The measured values were: temperature, relative humidity, wind speed and wind direction. Figure 11 shows the location of the case study in orange and the location of the weather stations in yellow.
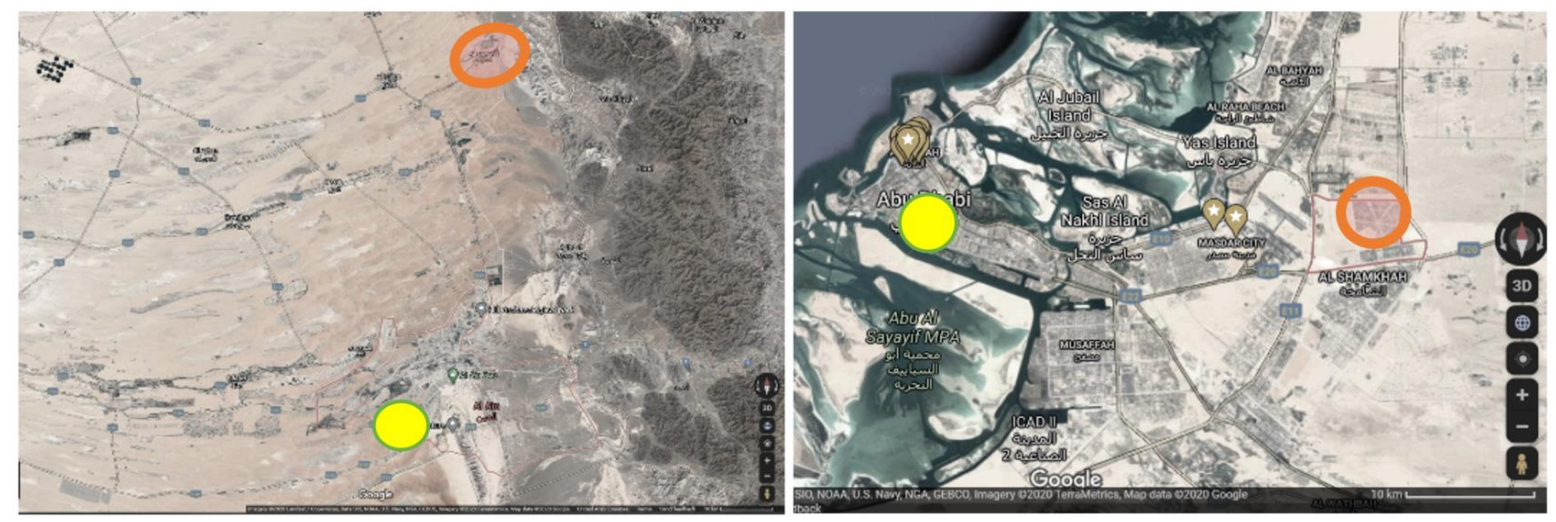

Figure 11. Site measurement location for the Al Ain City and Abu Dhabi City.

\subsection{Modeling and Simulations}

The modeling, the simulations and the PMV calculations are done with ENVI-met software 4.0. This is a piece of Computational Fluid Dynamic software that considers factors such as heat fluxes, wind, heat transfer, evapotranspiration. ENVI met has three different sizes in the modeling environment, respectively: $100 \times 100 \times 40,180 \times 180 \times$ $35,250 \times 250 \times 30$. The difference between one size and the other is the scale of detail introduced in the models. In the scale $100 \times 100 \times 40$, for example, the shading device can be less detailed in shape and form than the scale $250 \times 250 \times 30$. However, in the first case, the simulations will run faster due to the level of low detailing. The models of this study refer to the scale $100 \times 100 \times 40$ as it is the least time-consuming modeling environment to simulate. The software environment has been modified based on the previous studies done for Abu Dhabi Downtown OTC calculation [21]. The soil layers are modified in order to have the heat fluxes close to the natural conditions. Previously, the standard software templates overestimated the mean radiant temperature. 
The trees are modified based on the characteristics of the local trees. Local trees, also called "Ghaf" trees, are resistant to the extreme hear of the summer, provide shade and require less irrigation than imported trees that are not native in the country. This tree requires low maintenance due to high adaptability in the harsh weather conditions (native tree). In the modeling, the changes are done to the height of the trunk height, roots length, foliage albedo and the leaf type (LAD 2, Height 5, foliage albedo 0.7). All these changes are done with the scope of creating a realistic built environment. The materials of the walls of the buildings are also modified based on the information collected. The pavement and asphalt have new characteristics based on the site conditions [29].

Figure 12 shows the shading device design reference referred to in a previous study done in the main island of Abu Dhabi from the same author. The design was initially sketched in AutoCAD and then imported in RHINO, where it was analyzed through plug-ins such as grasshopper (not part of this study). The application in ENVI-met refers to this design, but it is simplified due to the ENVI-met 4.0 limited design possibilities. However, the material properties are as described above, close to the designed shading structure [29].



Figure 12. Shading device reference used in a previous study applied in ENVI-met models [29].

The simulation principle is to use the model created and insert the boundary conditions. These conditions refer to air temperature, relative humidity and wind speed data collected form a rural station located in the closest city to the town considered in this study, which is Al Ain. The detailed description of the boundary condition is shown in the annex. The boundary conditions include the following: the initial values of air temperature, relative humidity, wind speed and soil moisture. The areas under the trees in the models have irrigated soil, which explains the high moisture. The areas under the shading devices have pavement. The boundary conditions are shown for both locations of the two case studies, Al Ain District and Abu Dhabi District. Figure 13 shows the 3D (3 dimension) of the scenario1 for each district, Figure 14 shows scenario 2, Figure 15 shows scenario 3, Figure 16 shows scenario 4, Figure 17 shows scenario 5, Figure 18 shows scenario 6. The simulation time is relatively long. Passing from one scenario to the other, the reduction in the vegetation is notable, as is the replacement with the shading devices. The six scenarios based on the proportion of the green and shading are reflected in the 3D based on the AutoCAD drawings. Generally, the models with more vegetation are the ones to take more time in the simulation. The post-processor in ENVI-met goes from Biomet, where the PMV values are calculated and then to Leonardo, where the images and the final values are taken. These values are then elaborated in Matlab in order to obtain the compared values. The green colors of the images represent the trees, the red color represents the houses and the rose color the shading. 

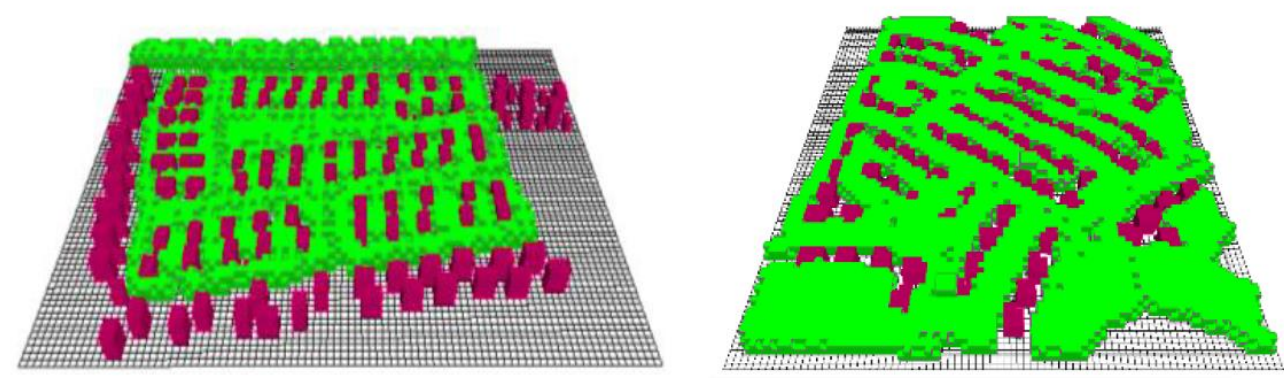

Figure 13. ENVI-met 3Dimension of scenario 1, for the Al Ain District and Abu Dhabi District (model scale 100×100).


Figure 14. ENVI-met 3Dimension of scenario 2, for the Al Ain District and Abu Dhabi District (model scale $100 \times 100$ ).


Figure 15. ENVI-met 3Dimension of scenario 3, for the Al Ain District and Abu Dhabi District (model scale 100 $\times 100$ ).


Figure 16. ENVI-met 3Dimension of scenario 4, for the Al Ain District and Abu Dhabi District (model scale 100 $\times 100$ ).
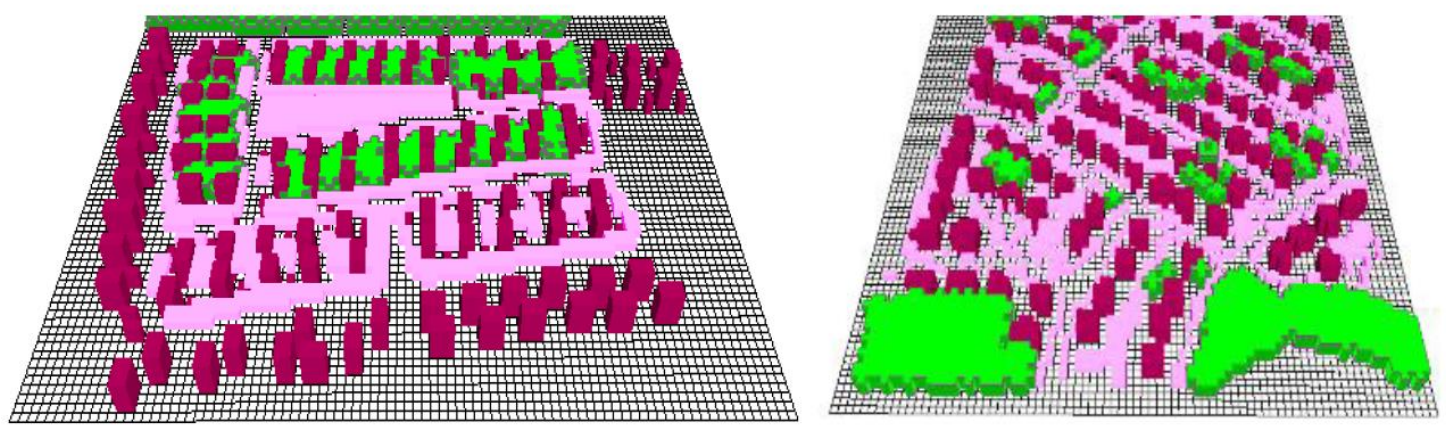

Figure 17. ENVI-met 3Dimension of scenario 5, for the Al Ain District and Abu Dhabi District (model scale $100 \times 100$ ). 



Figure 18. ENVI-met 3Dimension of scenario 5, for the Al Ain District and Abu Dhabi District (model scale $100 \times 100$ ).

\section{Results}

Figure 19 shows the PMV values for $\mathrm{Al}$ Ain and Figure 20 shows the PMV values for Abu Dhabi. Even though in the temperature graph there is no big change from one scenario to the other, in the relative humidity and in the PMV values the scenarios with more shading devices (Scenario 6) show better values. The PMV has improved by 0.7 at hour 14.00 in the $\mathrm{Al}$ Ain case study (Figure 19) and by 1 point in the same hour in the Abu Dhabi case study (Figure 20). Figure 9 shows the relative humidity values in the $\mathrm{Al}$ Ain case study and Figure 10 shows the relative humidity in the Abu Dhabi case study. For the same hour, 14.00, the difference between the base case and Scenario 6 for the $\mathrm{Al}$ Ain is 0.2 (Figure 21) and for the Abu Dhabi is 0.8 (Figure 22). Scenario 6 has 100\% shading structures. This means an important improvement in the outdoor thermal comfort. However, scenario 3 in the first case study and Scenario 5 in the second case study show improvement of the PMV in peak hours. In this scenario, the vegetation is organized in the center of the district and the shading devices surround the area. The biggest reduction in the PMV is in the peak hours, between 10 a.m. and 5 p.m. These are the most critical hours of the day, when walking in outdoor conditions is not healthy due to the extreme heat. The study day, as mentioned above, is a typical summer day, 18 June 2019.

Referring to the PMV classification, values above 3 are considered as 'boiling hot' and cause extreme heat stress. In the results presented, the values of the PMV are above 4 in peak hours (11.00-16.00). Although, the results are an average of the districts (except the buildings).

Figure 23 shows the result in PMV of the Abu Dhabi District for 2.00 p.m. of Summer 2019 scenario 1and 2, Figure 24 scenario 3 and 4, Figure 25 for scenario 5 and 6 . The minimum and the maximum levels of PMV are added near each image. The images show a reduction in the OTC from one option to the other. The colors show a clear difference between the different strategies. The graphs shown in Figures A1 and A2 in the Appendix A show the air temperatures for both case studies. The difference in air temperature between the base case and Scenario 6 for hour 14.00 is 0.3 (Figure A1), and in the Al Ain case study and Abu Dhabi case study it is 0.4 degrees Celsius (Figure 13). 




Figure 19. PMV results of the Al Ain District for Summer 2019.



Figure 20. PMV results of the Abu Dhabi District for Summer 2019. 


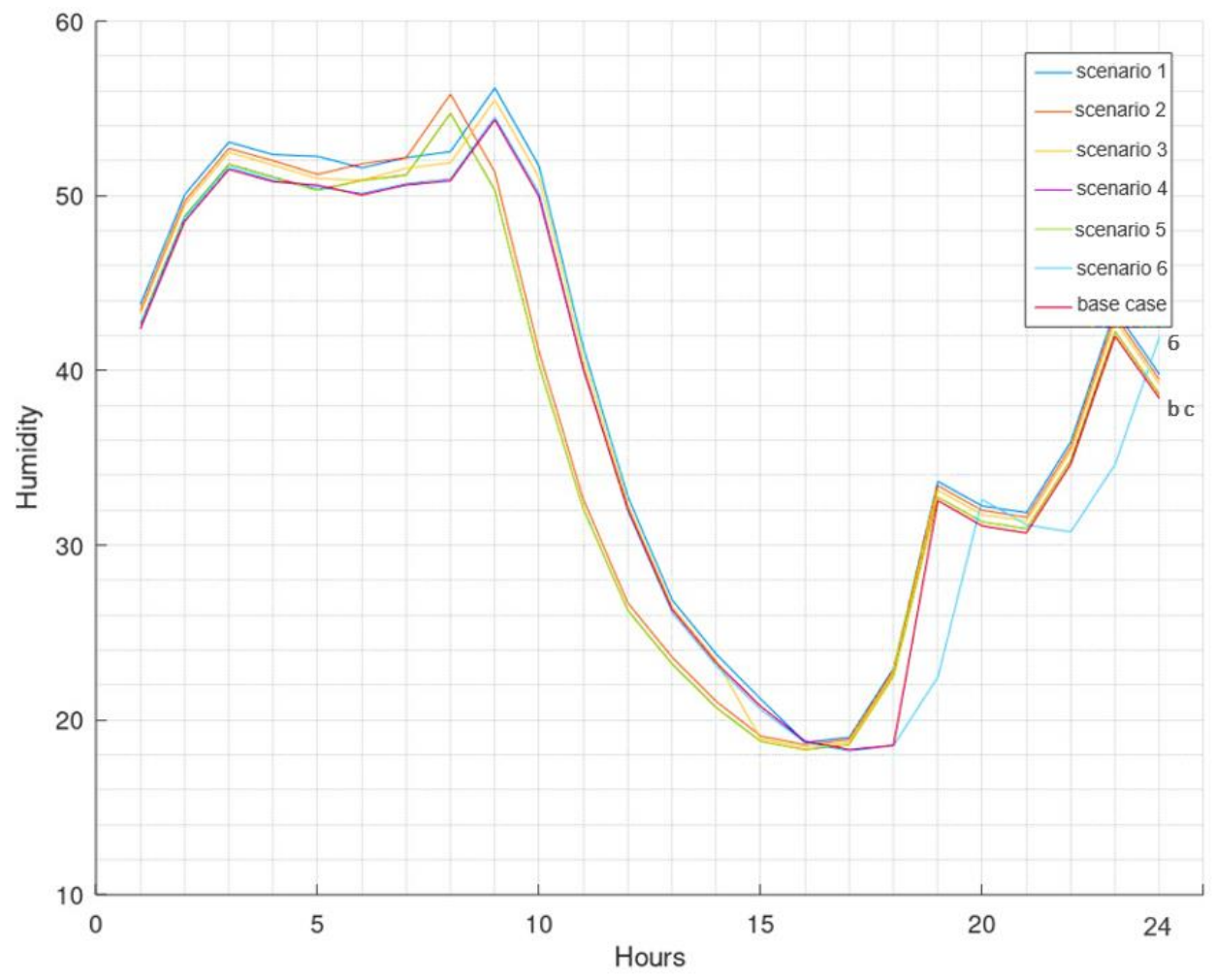

Figure 21. Relative humidity values of the Al Ain District for Summer 2019.

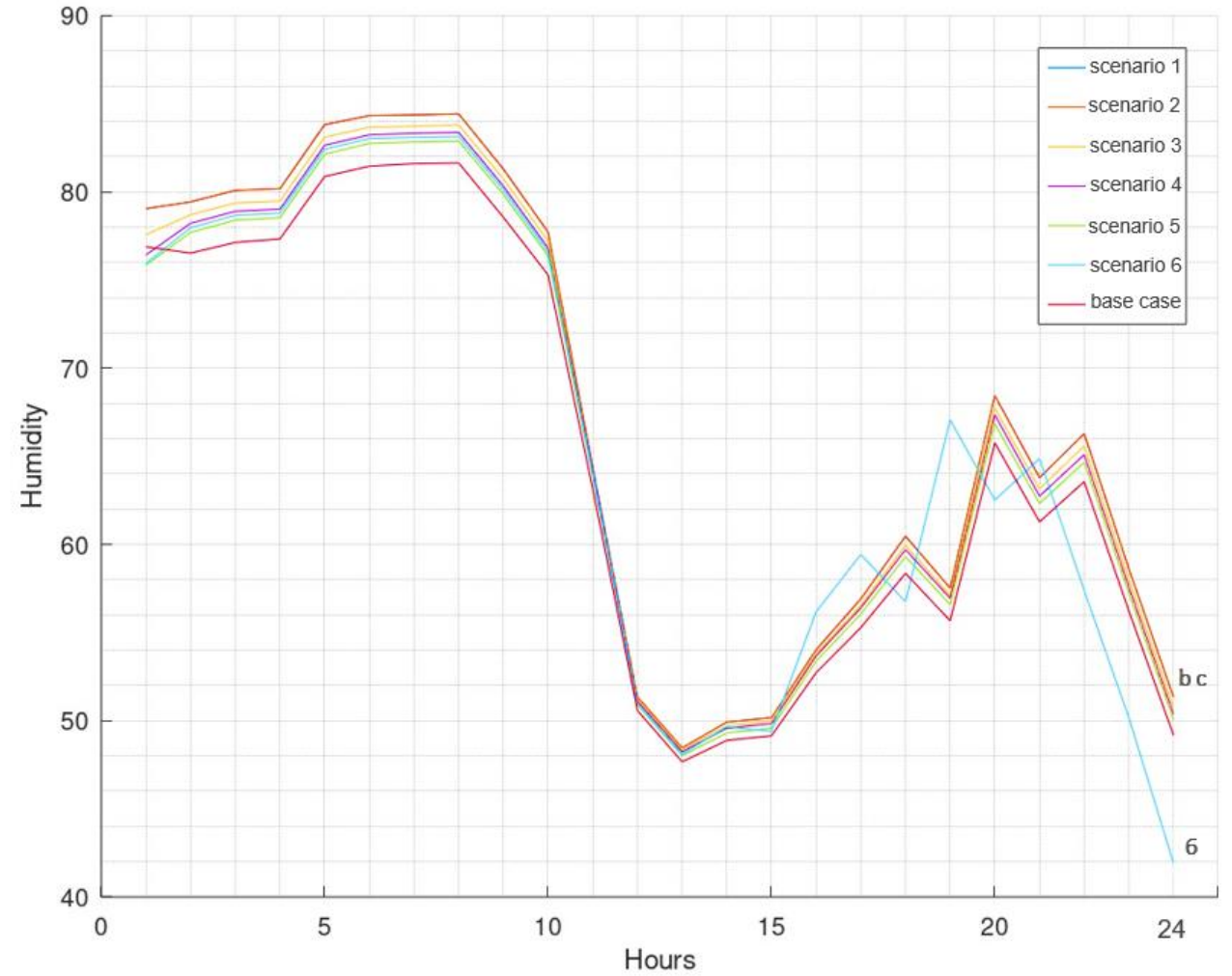

Figure 22. Relative humidity values of the Abu Dhabi District for Summer 2019. 

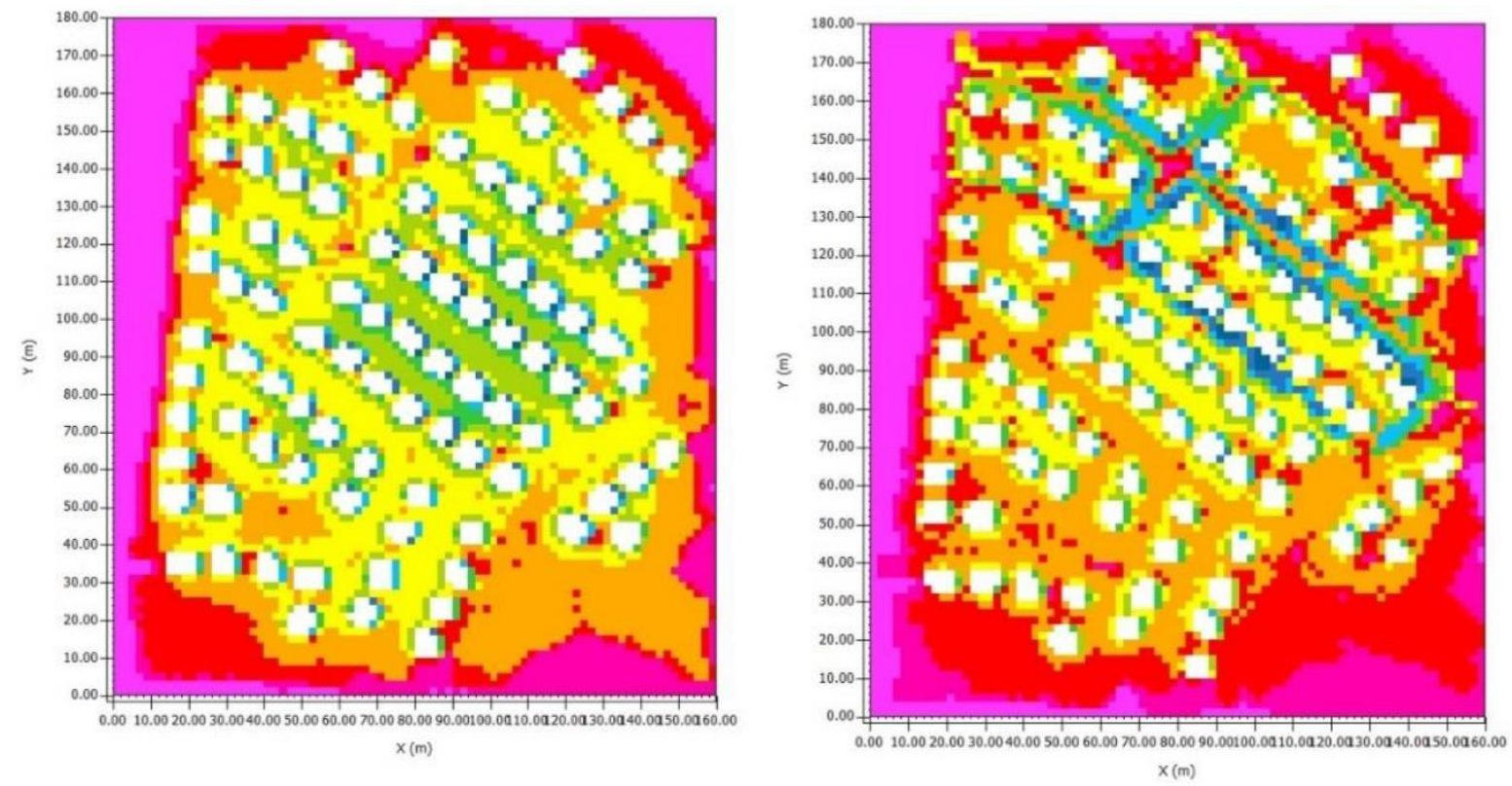

Figure 23. ENVI met results in PMV of the Abu Dhabi District for 2.00 p.m. of Summer 2019 scenario 1 (min 3.29-max 5.45), scenario 2 ( $\min 2.89-\max 5.44)$.
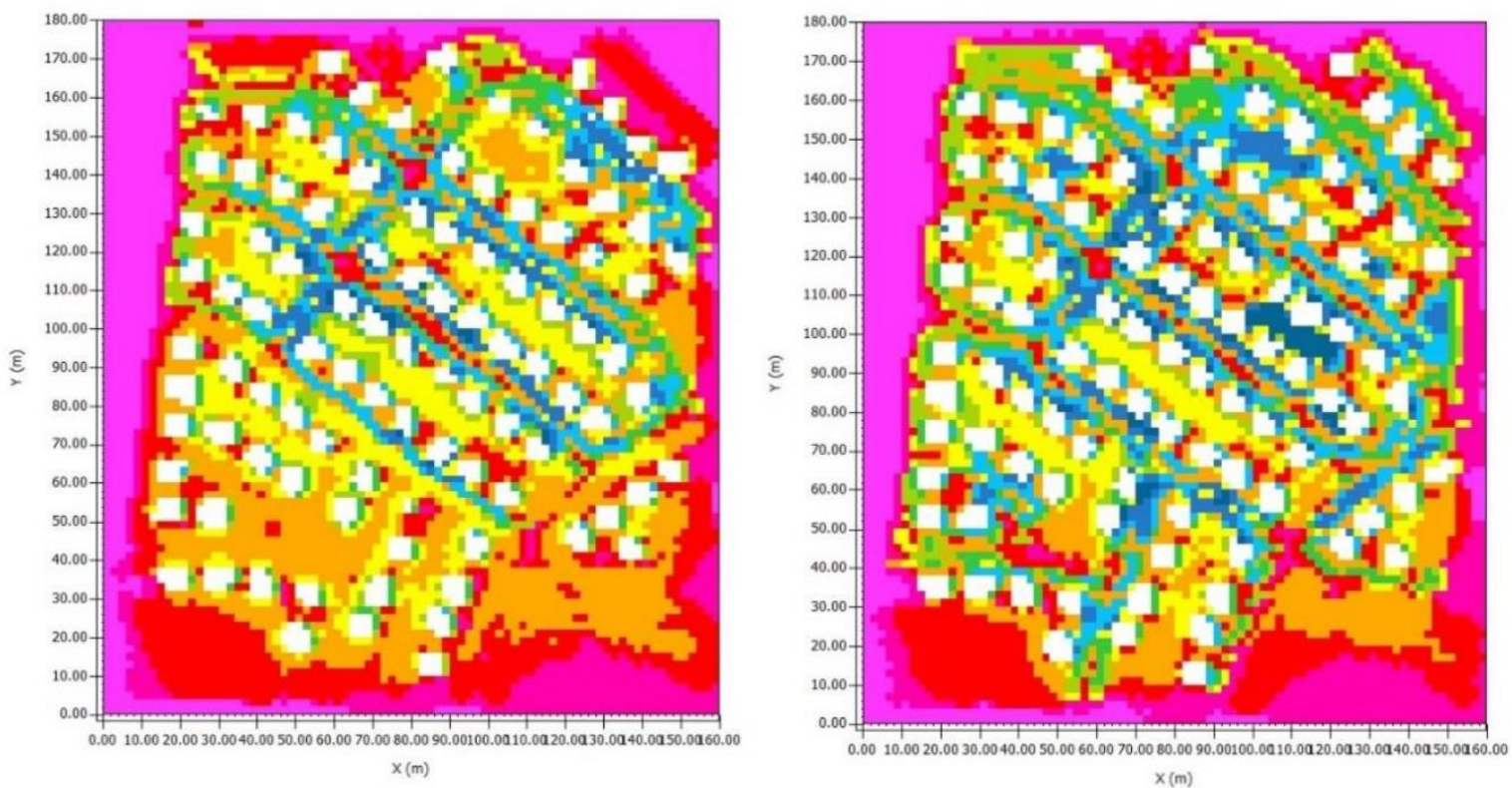

Figure 24. ENVI met results in PMV of the Abu Dhabi District for 2.00 p.m. of Summer 2019 scenario 3 (min 3.09-max 5.45), scenario 4 ( $\min 3.08-\max 5.45)$. 


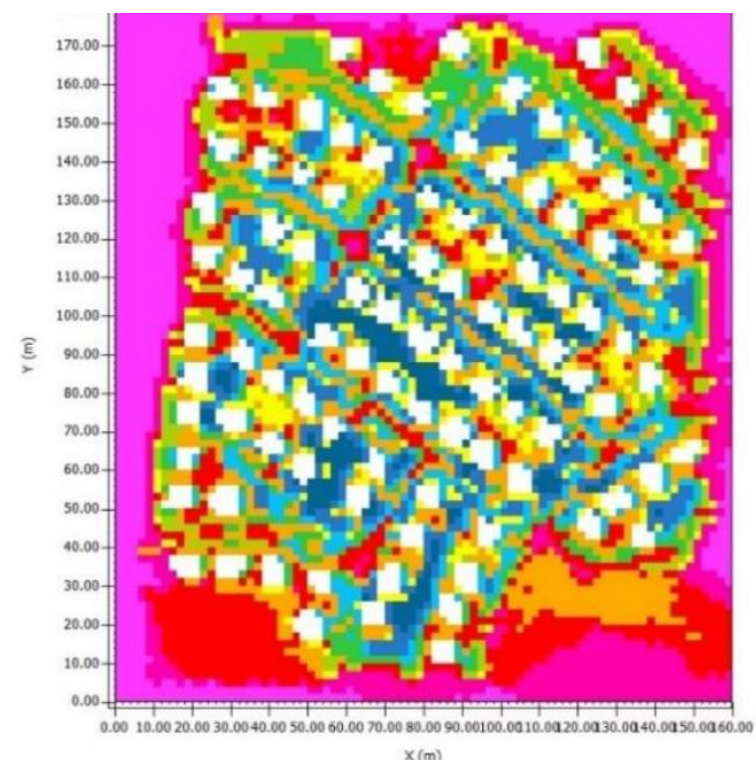

$\mathrm{X}(\mathrm{m})$

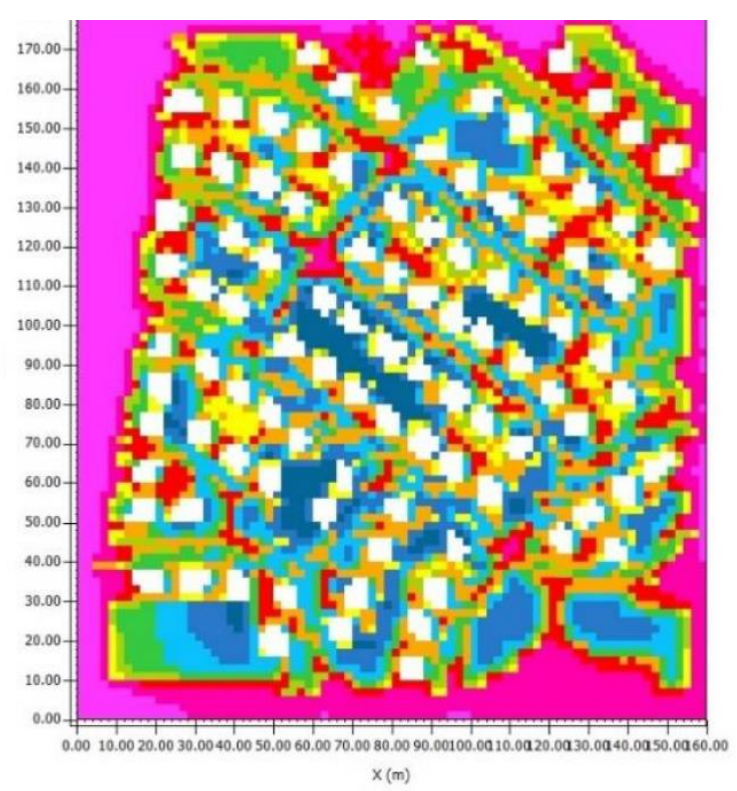

$x(m)$

Figure 25. ENVI met results in PMV of the Abu Dhabi District for 2.00 p.m. of Summer 2019 scenario 5 (min 3.10-max 5.46), scenario 6 ( $\min 3.09-\max 5.46)$.

\section{Discussion}

Based on the PMV classification, values above 3 are considered as 'boiling hot' and cause 'extreme heat stress'. In the results presented, the values of the PMV are above 4 in peak hours 11.00-16.00. These results are an average of the districts (except the buildings), meaning that the PMV under the shading structures or the trees might have a greater improvement. The tool to calculate the average values is Matlab and is based on the post-processed files received from ENVI-met. Considering the extreme temperatures in the region, the improvement in the OTC within the same 'class' is relevant as it improves walkability.

The difference between the best-performing scenario, in this case Scenario 6, of both case studies (Al Ain District and Abu Dhabi District) is shown in Figure 26. The biggest improvement in this strategy seems to be in Abu Dhabi, with the OTC value reduced by 1 . It is important to mention that the PMV is related to the thermal perception or the thermal stress of the pedestrians. This study shows that the shading devices are perceived as better shade providers, although it was expected that the green scenarios would have better results due to the evapotranspiration process. Another factor contributing to the PMV is the relative humidity. The results values can be attributed to the high humidity level in the city. Therefore, shading devices perform better than vegetation, where the evapotranspiration process is present and increases the discomfort levels.

The trees used in the models of the study are modified to adapt to the local trees. They are resilient to harsh climates and provide relatively a large amount of shade. The leaves of this tree are not broad due to extreme heat and this might reduce the evapotranspiration process (also in relation to external conditions). Also, in the Al Ain case study, the impact of Scenario 6 on improving the OTC is relative. The values of the air temperature in the boundary conditions showed that the same day has different values in a coastal city such as Abu Dhabi and in a desert city such as Al Ain. 


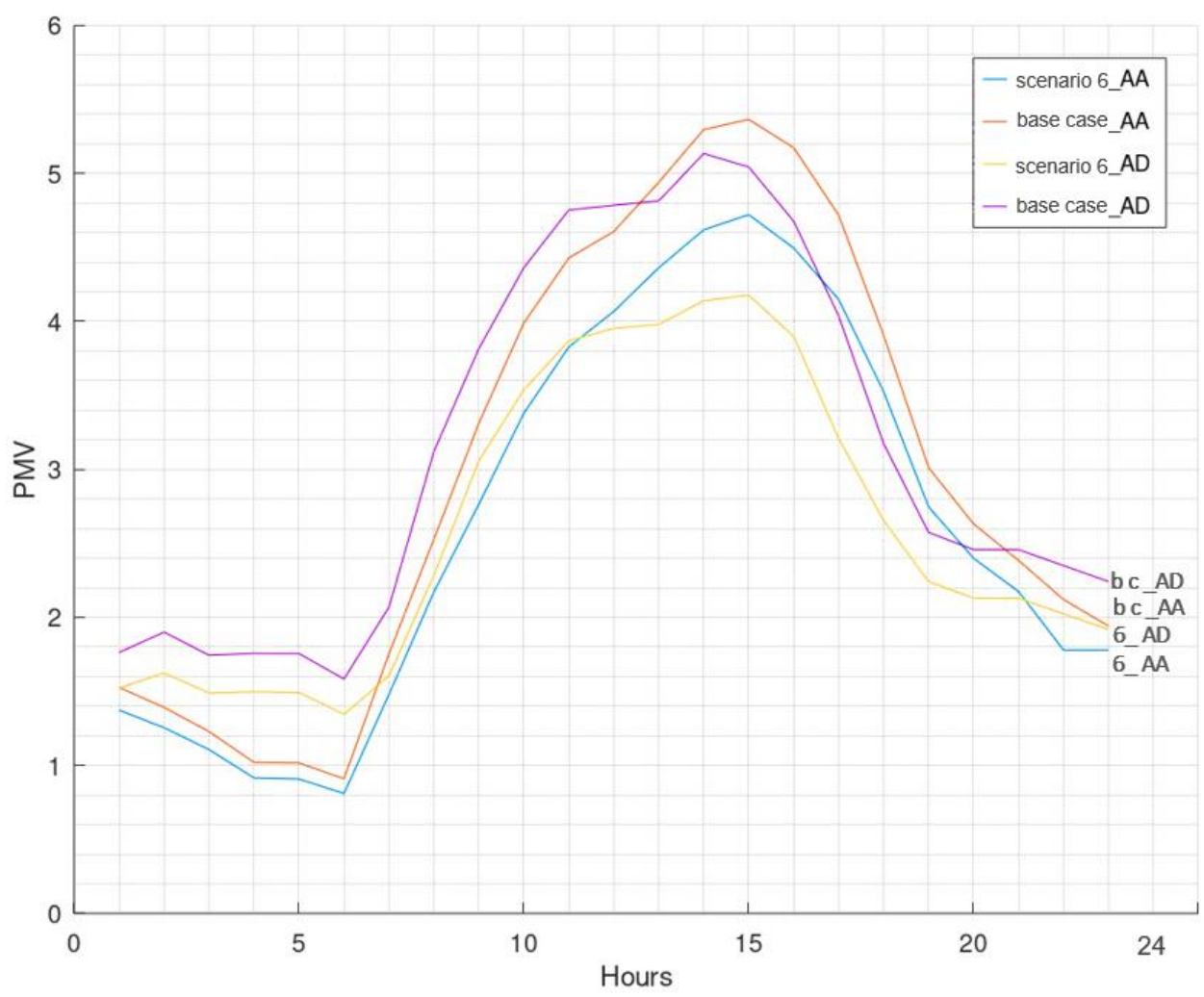

Figure 26. PMV values comparison: AL Ain District versus Abu Dhabi District for Summer 2019.

\section{Conclusions}

The results show that the shading devices have a better impact on the reduction in the PMV. Among the different scenarios analyzed, Scenario 6 in both cases shows the best OTC values. Scenario 6 has 100\% shading devices. This result can be explained by the impact of a shading device on cooling surface temperatures compared to the vegetation. Moreover, the values for Scenario 3 in the first case study and Scenario 5 in the second case study, where the vegetation is centralized in the common area of the district, also show a relative improvement. It was expected that the vegetation would have a more positive impact on reducing the PMV (compared to the shading devices) due to the evapotranspiration process. Also, the typology of the vegetation selected for this study refers to local vegetation (LAD 2, Height 5, foliage albedo 0.7 ), whose leaves are not broad due to the extreme heat. This might explain the limited evapotranspiration process. The comparison of the six scenarios in each case study refers to the respective base case.

This study recommendation for architects, urban planners and landscape designers is to incorporate, whenever possible, urban shading structures into the landscape (currently the attention is towards trees and vegetation). Abu Dhabi and Al Ain are fast growing cities, and such a study can add to the information available used by developers. The investigation adds information to the current applied strategies in retrofitting cities. Within the same country, the cities have different microclimates. Therefore, the strategies used in urban areas have different impacts on the OTC. It is relevant to conduct an OTC study before retrofitting an urban area. The higher number of shading structures used improves the OTC significantly more. However, further investigations need to be done with more detailed models in order to understand the impact of the urban shading structure shape and material. Perhaps the addition of other elements, such as water features, might bring further improvements to the OTC [30].

The analysis in this study is based on models previously validated in a similar study; therefore, the uncertainty calculation is not included [23]. However, there is more work needed in understanding how the configuration of each scenario might impact the OTC. The 
configuration or the distribution of trees and shading devices in the landscape treatment can be quite large. This study was referring mainly to the percentage distribution of these elements and the impact on the OTC.

Furthermore, a longer period of the year should be considered and applied. This study considered only a typical summer day. The autumn and winter are also of great interest for this investigation. In the different seasons, the humidity levels change so the impact of the shading devices, vegetation and water features is expected to vary. Also, other cities from the country need to be investigated on their behavior under this kind of intervention in order to have better outdoor thermal conditions and improve walkability for a healthier population.

This study refers to the city of Abu Dhabi and Al Ain with a hot arid climate (and different microclimates in terms of humidity levels). The findings of the analysis can be used in countries with the same or similar climate and microclimate. Countries such as Saudi Arabia, Qatar, Bahrein, Kuwait, etc., have hot arid climates, much like the United Arab Emirates (Arabian Peninsula); therefore, this study has a wide range of applications.

Author Contributions: Conceptualization, L.B. and R.A.; methodology, L.B. and K.Y.; software, L.B.; validation, L.B.; formal analysis, L.B.; investigation, L.B. and R.A.; resources, L.B. and K.Y.; data curation, L.B. and R.A.; writing-original draft preparation, L.B., R.A., A.A. (Amna Aldarmaki), A.A. (Atmah Aldhaheri), A.A. (Asma Alneyadi), S.A., M.K.; writing-review and editing, L.B., K.Y., R.G. and M.J.; visualization, L.B.; supervision, L.B. and K.Y.; project administration, L.B. and K.Y.; funding acquisition, L.B. All authors have read and agreed to the published version of the manuscript.

Funding: This research was funded by the UAEU, Sure Plus Program, grant number 1006.

Acknowledgments: The authors would like to thank the UAEU for supporting the study and allowing for the measurements to take place. A valuable contribution and technical support were given by Rashed Al Shaali.

Conflicts of Interest: The authors declare no conflict of interest and the funders had no role in the design of the study; in the collection, analyses, or interpretation of data; in the writing of the manuscript, or in the decision to publish the results.

\section{Appendix A}

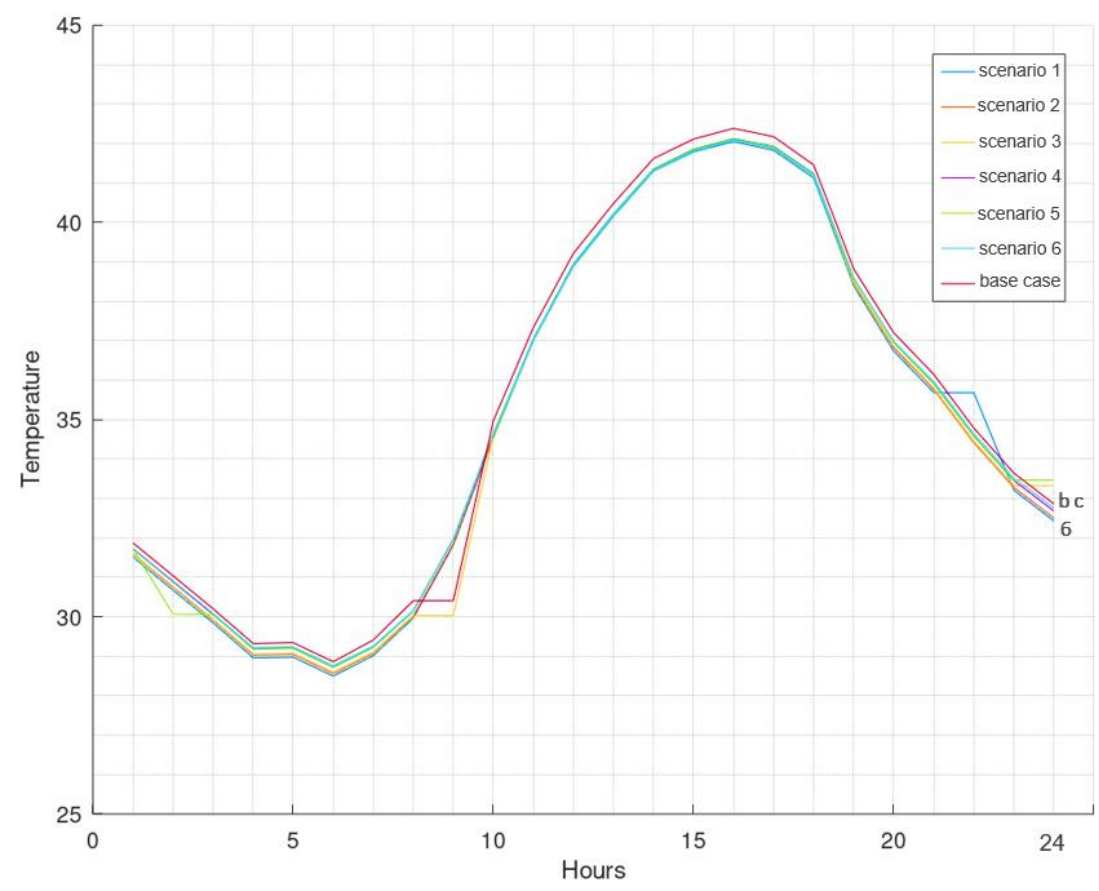

Figure A1. Air temperature results of Al Ain District for Summer 2019. 


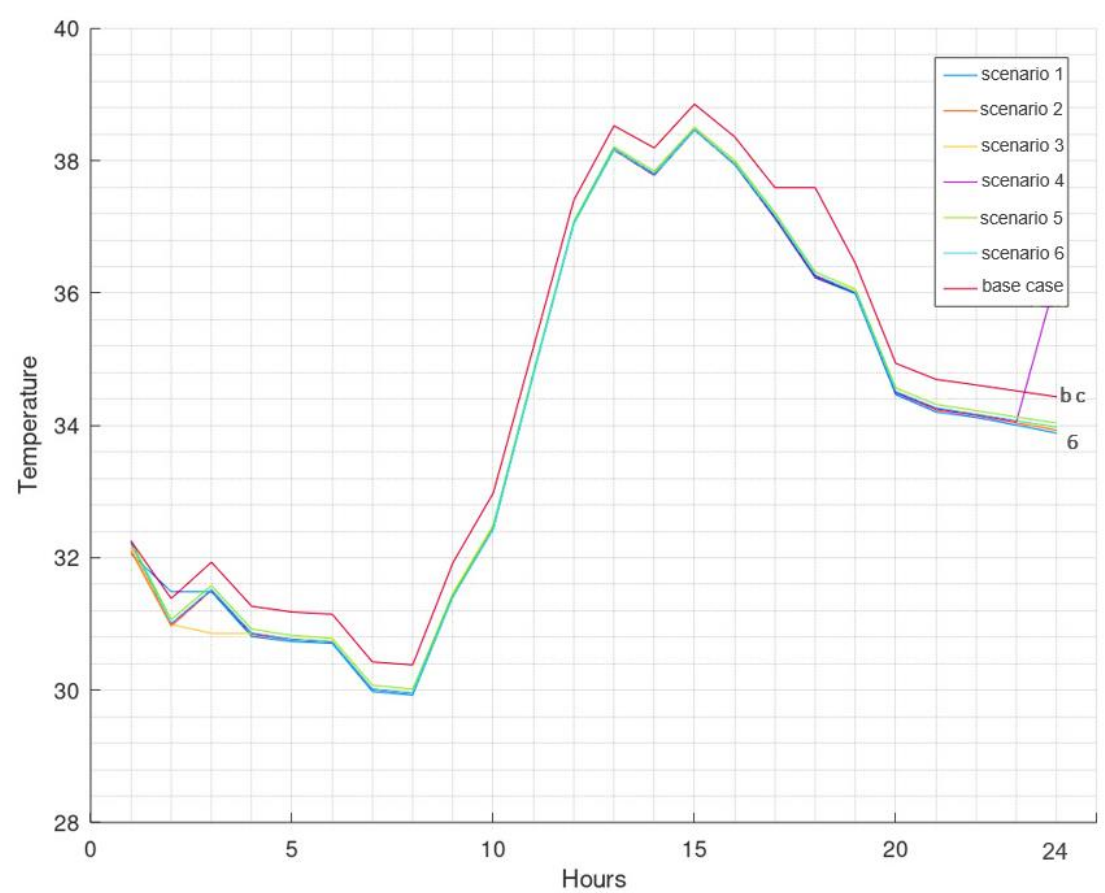

Figure A2. Air temperature results of Abu Dhabi District for Summer 2019.

Al Ain Boundary Conditions for ENVI-met Start Simulation at Day (DD.MM.YYYY): Start Simulation at Time (HH:MM:SS):

Total Simulation Time in Hours:

Wind Speed in $10 \mathrm{~m}$ ab. Ground [m/s]

Wind Direction (0:N..90:E..180:S..270:W..)

Roughness Length z0 at Reference Point [m]

Initial Temperature Atmosphere [K]

Specific Humidity in $2500 \mathrm{~m}$ [g water $/ \mathrm{kg}$ air] $=7$

Relative Humidity at $2 \mathrm{~m} \mathrm{[ \% ]} \quad=62.85$

$\%$ End main data

[OUTPUTTIMING]

Output interval main files (min)

$=60.00$

Output interval log files (min)

$=30.00$

Include Nesting Grids in Output (0:n,1:y)

[SOLARADJUST]

Factor of shortwave adjustment $(0.5$ to 1.5$)=0.90$

[CLOUDS]

Fraction of LOW clouds $(x / 8)$

Fraction of MIDDLE clouds (x/8)

$=1.00$

Fraction of HIGH clouds $(x / 8)$ $=2.00$

[SOILDATA]

$=1.00$

Initial Temperature Upper Layer $(0-20 \mathrm{~cm}) \quad[\mathrm{K}]=301.15$

Initial Temperature Middle Layer $(20-50 \mathrm{~cm})[\mathrm{K}]=297.50$

Initial Temperature Deep Layer (below $50 \mathrm{~cm}$ ) $[\mathrm{K}]=293.00$

Relative Humidity Upper Layer $(0-20 \mathrm{~cm}) \quad=95.00$

Relative Humidity Middle Layer $(20-50 \mathrm{~cm}) \quad=90.00$

Relative Humidity Deep Layer (below $50 \mathrm{~cm}$ ) $\quad=85.00$

[SIMPLEFORCE]

Hour $00 \mathrm{~h}$ [Temp, rH] $=307.63,31.54$

Hour $01 \mathrm{~h}[\mathrm{Temp}, \mathrm{rH}]=306.46,36.48$

Hour 02 h [Temp, rH] $=305.38,44.52$ 


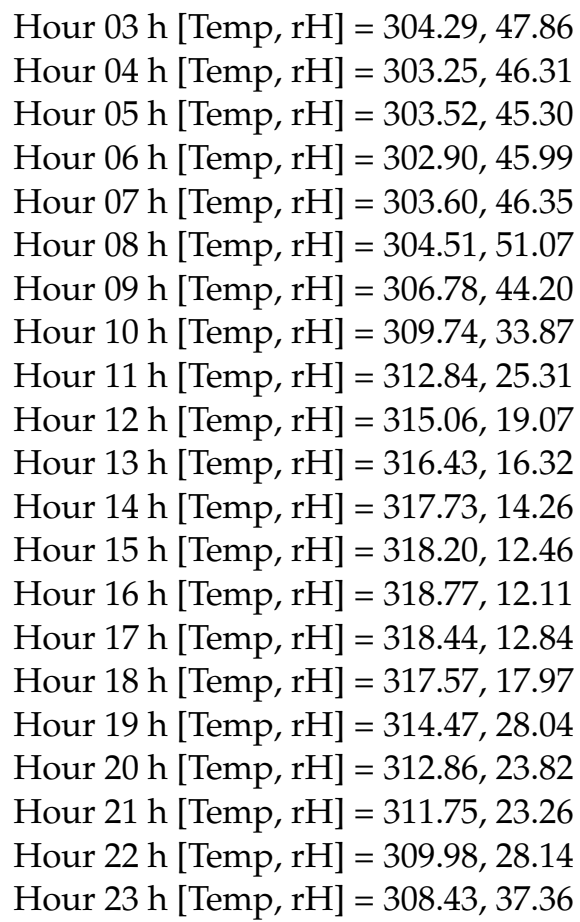

Abu Dhabi Boundary Conditions for ENVI-met

Start Simulation at Day (DD.MM.YYYY):

Start Simulation at Time (HH:MM:SS):

Total Simulation Time in Hours:

$=18.06 .2019$

Wind Speed in $10 \mathrm{~m}$ ab. Ground $[\mathrm{m} / \mathrm{s}] \quad=3.15$

Wind Direction (0:N..90:E..180:S..270:W..) $=311$

Roughness Length $\mathrm{z} 0$ at Reference Point $[\mathrm{m}] \quad=0.01$

Initial Temperature Atmosphere $[\mathrm{K}] \quad=310.44$

Specific Humidity in $2500 \mathrm{~m}$ [g water $/ \mathrm{kg}$ air] $=7$

Relative Humidity at $2 \mathrm{~m} \mathrm{[ \% ]} \quad=68.29$

$\%$ End main data .....

[OUTPUTTIMING]

Output interval main files (min)

Output interval log files (min) $\quad=30.00$

Include Nesting Grids in Output (0:n,1:y) $\quad=0$

[SOLARADJUST]

Factor of shortwave adjustment ( 0.5 to 1.5$)=0.90$

[CLOUDS]

Fraction of LOW clouds $(x / 8) \quad=1.00$

Fraction of MIDDLE clouds $(\mathrm{x} / 8) \quad=2.00$

Fraction of HIGH clouds $(\mathrm{x} / 8) \quad=1.00$

[SOILDATA]

Initial Temperature Upper Layer $(0-20 \mathrm{~cm}) \quad[\mathrm{K}]=301.15$

Initial Temperature Middle Layer $(20-50 \mathrm{~cm})[\mathrm{K}]=297.50$

Initial Temperature Deep Layer (below $50 \mathrm{~cm}$ ) $[\mathrm{K}]=293.00$

Relative Humidity Upper Layer $(0-20 \mathrm{~cm}) \quad=95.00$

Relative Humidity Middle Layer $(20-50 \mathrm{~cm}) \quad=90.00$

Relative Humidity Deep Layer (below $50 \mathrm{~cm}$ ) $\quad=85.00$

[SIMPLEFORCE]

Hour $00 \mathrm{~h}$ [Temp, rH] $=305.15,84.00$

Hour $01 \mathrm{~h}[\mathrm{Temp}, \mathrm{rH}]=304.15,84.00$

Hour $02 \mathrm{~h}[\mathrm{Temp}, \mathrm{rH}]=305.15,84.00$ 


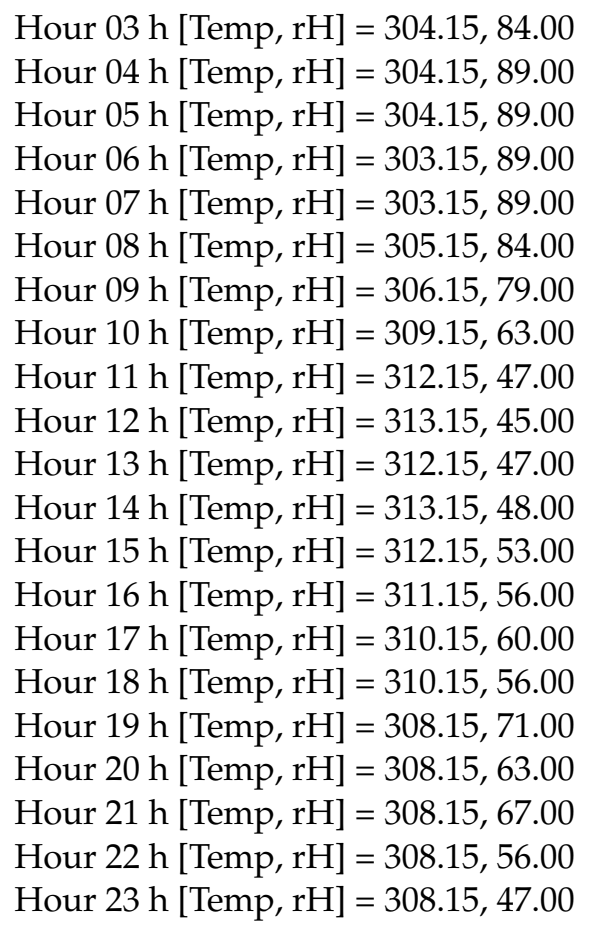

\section{References}

1. Krarti, M.; Dubey, K. Review analysis of economic and environmental benefits of improving energy efficiency for UAE building stock. Renew. Sustain. Energy Rev. 2018, 82, 14-24. [CrossRef]

2. World Bank's database. Electric Power Consumption; World Bank: Washington, DC, USA, 2014.

3. World Energy Council. Policies for the Future; 2011 Assessment of Country Energy and Climate Policies; World Energy Council: London, UK, 2011.

4. Khondaker, M.A.; Hasan, A.; Rahman, M.; Malik, M.S.; Shafiullah, K.; Muhyedeen, M. Greenhouse gas emissions from energy sector in the United Arab Emirates-An overview. Renew. Sustain. Energy Rev. 2016, 59, 1317-1325. [CrossRef]

5. Alfaris, M.-A.F.; Juaidi, A.F. Energy retrofit strategies for housing sector in the arid climate. Energy Build. 2016, 131, 158-171. [CrossRef]

6. Statista Research Department. Consumption of Electricity in Dubai in 2019, by Sector; Statista: Hamburg, Germany, 2020.

7. Agrawal, S.K.; Pallathucheril, V.; Sangapala, P. Affordable Housing for Emiratis in the United Arab Emirates: The Case Study of Ras Al Khaimah. Hous. Policy Debate 2020, 30, 1-26. [CrossRef]

8. Friess, W.A.; Rakhshan, K.; Hendawi, T.A.; Tajerzadeh, S. Wall insulation measures for residential villas in Dubai: A case study in energy efficiency. Energy Build. 2012, 44, 26-32. [CrossRef]

9. Clair, P.S. Low-Energy Design in the United Arab Emirates-Building Design Principles. BEDP Environ. Des. Guid. 2009, 1-10. Available online: http:/ / www.jstor.org/stable/26151847 (accessed on 1 March 2021).

10. Aboulnaga, M.M. A roof solar chimney assisted by cooling cavity for natural ventilation in buildings in hot arid climates: An energy conservation approach in Al-Ain city. Renew. Energy 1998, 14, 357-363. [CrossRef]

11. Taleb, H.M. Using passive cooling strategies to improve thermal performance and reduce energy consumption of residential buildings in U. A. E. buildings. Front. Archit. Res. 2014, 3, 154-165. [CrossRef]

12. Lin, Y.C.; Tsai, P.T.; Liao, T.K.; Huang, C.C. Effects of thermal comfort and adaptation on park attendance regarding different shading levels and activity types. Build. Environ. 2013, 59, 599-611. [CrossRef]

13. Gaitani, M.S.N.; Mihalakakou, G. On the use of bioclimatic architecture principles in order to improve thermal comfort condition in outdoor spaces. Build. Environ. 2005, 42,317-324. [CrossRef]

14. Taleb, H. Urbanizing the deserts of Dubai: An outdoor thermal comfort case study of Dubai International Academic City, UAE. In Sustainable City VII; WIT Press: Southampton, UK, 2012; Volume 1, pp. 85-95.

15. Mohamed, A. The Impact of Different Urban Configurations on Outdoor Thermal Comfort: A Case Study of the Military Camps in Abu Dhabi, UAE; The British University in Dubai (BUiD): Dubai, United Arab Emirates, 2016.

16. Hamdan, D.M.A.; de Oliveira, F.L. The impact of urban design elements on microclimate in hot arid climatic conditions: Al Ain City, UAE. Energy Build. 2019, 200, 86-103. [CrossRef]

17. Baca, E.E.S.; Tsai, I.T. A Model-Based Approach to Measuring the Effect of Shading on Outdoor Thermal Comfort. Int. J. Eng. Technol. 2015, 7, 116-121. [CrossRef]

18. Dhariwal, J.; Manandhar, P.; Bande, L.; Marpu, P.; Armstrong, P.; Reinhart, C.F. Evaluating the effectiveness of outdoor evaporative cooling in a hot, arid climate. Build. Environ. 2019, 150, 281-288. [CrossRef] 
19. Nikolopoulou, K.S.M. Thermal comfort and psychological adaptation as a guide for designing urban spaces. Energy Build. 2003, 35, 95-101. [CrossRef]

20. Liu, W.; Zhang, Y.; Deng, Q. The effects of urban microclimate on outdoor thermal sensation and neutral temperature in hot-summer and cold-winter climate. Energy Build. 2016, 128, 190-197. [CrossRef]

21. Bande, L. Validation of UWG and ENVI-Met Models in an Abu Dhabi District, Based on Site Measurements. Sustainability 2019, 11, 4378. [CrossRef]

22. Reiche, D. Renewable Energy Policies in the Gulf countries: A case study of the carbon-neutral "Masdar City" in Abu Dhabi. Energy Policy 2010, 38, 378-382. [CrossRef]

23. Shawesh, R.; Mohamed, M. Post-occupancy evaluation of outdoor thermal comfort in hot arid zone. Int. J. Low-Carbon Technol. 2020, 2020, ctaa035. [CrossRef]

24. Hegazy, I.R.; Qurnfulah, E.M. Thermal comfort of urban spaces using simulation tools exploring street orientation influence of on the outdoor thermal comfort: A case study of Jeddah, Saudi Arabia. Int. J. Low-Carbon Technol. 2020, 15, 594-606. [CrossRef]

25. Fanger, P.O. Thermal comfort. Analysis and applications in environmental engineering. Therm. Comf. Anal. Appl. Environ. Eng. 1970, 1, 138.

26. Plan Abu Dhabi 2030-The Official Portal of the UAE Government. Available online: https://u.ae/en/about-the-uae/strategiesinitiatives-and-awards/local-governments-strategies-and-plans/plan-abu-dhabi-2030 (accessed on 21 December 2020).

27. ENVI-Met-Decode Urban Nature with ENVI-Met Software. Available online: https:/ / www.envi-met.com/ (accessed on 22 February 2021).

28. MATLAB. MathWorks-MATLAB \& Simulink. Available online: https://www.mathworks.com/products/matlab.html (accessed on 22 February 2021).

29. Bande, L. Heat Island Mitigation Strategies, with Focus on the Urban Shading Devices. The Case Study of Abu Dhabi Main Island, United Arab Emirates. Ph.D. Thesis, Masdar Institute of Science and Technology, Masdar City, United Arab Emirates, 9 March 2017.

30. AbuDhabi Public Parks. Available online: https://www.dmt.gov.ae/en/adm/Parks (accessed on 22 February 2021).

31. Data Sources-Climate-Data.org. Available online: https://en.climate-data.org/info/sources/ (accessed on 21 February 2021). 